\title{
Cristología en América Latina: retos y desafíos*
}

\author{
José Arlés Gómez A.**
}

Recibido: 5 de mayo de 2012 • Aprobado: 31 de agosto de 2012

\section{Resumen}

El presente artículo presenta un panorama general del estado de la cristología en América Latina, especialmente desde el contexto de los grandes retos y tareas que emergen del compromiso cristiano hoy, en un continente que se debate entre grandes paradojas y contradicciones, fruto de su largo proceso histórico-cultural y político de marginación, pobreza, exclusión y falta de compromiso con la construcción de una sociedad nueva desde el mensaje de Jesús de Nazareth.

Palabras clave: cristo, realidad, compromiso, cristología, comunidad.

* Artículo de avance investigativo desarrollado en el Grupo Ciencia-Espiritualidad, presentado como ponencia ante el I Coloquio de Cristología en la Facultad de Teología de la Universidad Santo Tomás, 2011.

** Docente del Doctorado en Educación, USTA, Bogotá; Posdoctor en Narrativa y Ciencia, Doctor en Teología de la Pontificia Universidad Urbaniana, Magister en Filosofía Latinoamericana, Especialista en Educación Sexual, Especialista en Educación y Filosofía Colombiana, Licenciado en Teología. Director del Grupo Ciencia-Espiritualidad; autor de varios artículos y libros sobre epistemologías emergentes, espiritualidad y teología. Correo electrónico: josegomeza@ ustadistancia.edu.co 


\title{
Christology in Latin America: challenges
}

\begin{abstract}
This article presents a general overview of the state of Christology in Latin America, especially from the context of the great challenges and tasks that arise from the Christian commitment today in a continent torn between great paradoxes and contradictions that result from its long historical-cultural and political process of marginalization, poverty, exclusion and lack of commitment with the construction of a new society from the message of Jesus of Nazareth.
\end{abstract}

Keywords: Christ, reality, commitment, christology, community.

\section{Antecedentes}

El Concilio Vaticano II incentivó de forma notable los estudios eclesiológicos y cristológicos. Muy especialmente en la década de los setenta -pero incluso hasta hoy, aunque a ritmo menor- se suceden "las cristologías", escritas por muchos de los más destacados teólogos cristianos de nuestro tiempo. Simultáneamente, suceden también los estudios sobre Jesús. En realidad, estos estudios empiezan a florecer con fuerza y con una nueva orientación en los años 50, con los trabajos pioneros de los grandes discípulos de Bultmann. Desde entonces, y sin la pretensión, que se considera ya imposible, de reconstruir su biografía, no han cesado de publicarse estudios de interés sobre Jesús, su vida y su mensaje. Podría incluso añadirse que los estudios históricos en torno a Jesús de Nazaret constituyen hoy un campo de investigación en plena ebullición, en el que se están publicando muchos e importantes libros, posiblemente más que en cualquier otra época anterior (Lois, 2006, pág. 3).

Por otro lado, es importante mencionar que, incluso hablando de unas líneas cristológicas por definirse en Latinoamérica y el Caribe, no se pueden dejar de lado algunas obras escritas especialmente desde la segunda mitad del siglo XX, que han inspirado a muchos teólogos y autores en cristología a repensar a Jesucristo desde estas latitudes. Entre ellos León-Dufour, X., Los evangelios y la historia de Jesús (1966); Bornkamm, Günther, Jesús de Nazaret (1975); Walter Kasper, Jesús, el Cristo (1989); Joachim Gnilka, Jesús de Nazaret, mensaje e historia ( 1995); John 
Meier, Un Judío Marginal. Juan y Jesús. El reino de Dios y compañeros y competidores. Los milagros de Jesús (1998-2003); Edward Schillebeeckx, Jesús la historia de un Viviente (1983); Rudolf Schnackenburg, La persona de Jesucristo reflejada en los cuatro Evangelios (1998); y Theissen, Gerd, La sombra del Galileo (2002).

\section{Introducción}

Presentar un panorama general del estado actual de la cristología en América Latina no es tarea fácil, En última instancia, se trata de una deuda de la cristología latinoamericana con todo el quehacer teológico actual: no convence un "seguimiento de Cristo" fundamentado en una especie de ausencia de la presencia real de Jesús de Nazaret, quien es también nuestro modelo y aliento en la construcción histórica de un compromiso con el amor y la justicia, y en el que, desde el futuro escatológico, nos alienta en el aquí y el ahora a luchar contra las fuerzas del anti reino, presentes en la historia de América Latina a través de los enormes desequilibrios socio-culturales y económicos, que nos reclaman revertir la misma historia en clave de reconciliación, justicia y solidaridad.

Por otro lado, determinar qué es la cristología latinoamericana constituye un problema teológico en sí mismo. La elaboración de la bibliografía de la cristología en América Latina, supone una clarificación del problema anterior; de hecho, hay innumerables publicaciones entre artículos, ensayos y libros, que dan testimonio del interés por el tema cristológico en nuestra región, especialmente desde la II Conferencia General del Episcopado celebrado en Medellín en 1968.

En efecto, desde la Conferencia celebrada en Medellín (Colombia), hasta la última Conferencia General del Episcopado celebrada en Aparecida (Brasil) en el 2007, ante la realidad progresiva de inhumanidad para la mayoría de hombres y mujeres de América Latina, se fue perfilando una pregunta desde la cristología: ¿podremos, desde Jesús de Nazaret, seguir ofreciendo los cristianos una respuesta liberadora, transformadora y plenificante a todos los seres humanos que sufren y esperan aún en Jesús, en un continente signado por la pobreza, la injusticia y la falta de solidaridad? Si esto es así ¿cuáles han de ser las acciones que iluminadas por el mismo Jesús, tendríamos qué realizar en América Latina?, ¿qué participación tomaríamos en su proyecto histórico en favor del marginado, del excluido social, cultural y espiritualmente? Caben incluso dos preguntas más: ¿qué rostro de Dios debemos presentar?, y ¿cuál sería el proyecto de humanidad que tendríamos qué forjar desde el seguimiento de Jesucristo? 
Estas y otras muchas preguntas, nos llevan a pensar que los presupuestos metodológicos de la cristología latinoamericana, dan un fuerte énfasis al carácter liberador del mismo Jesús de la historia, y nos sitúan frente a una realidad que se trata de transformar desde sus profundas contradicciones y paradojas, con el supuesto histórico de ser América Latina un continente que ha sido evangelizado por cinco siglos, donde, desde la época de la conquista, la figura de un Cristo crucificado y doliente nos habla de esa realidad de inhumanidad, en la que millones de mujeres y hombres han padecido, y que colocan en evidente contradicción nuestra fe cristiana con la realidad histórica y social. En efecto, el hablar de cristología en América Latina, es ciertamente remitirnos a un largo proceso histórico, que hunde sus bases en las complejas raíces pluriétcnicas de nuestros pueblos latinoamericanos, en las que, pese a los errores del pasado, aún es posible ofrecer desde la experiencia eclesial, como dice Aparecida, el encuentro con un Jesús de la vida que da Vida en abundancia (Jn 10:10), frente a los signos de muerte, violencia e injusticia en que vive nuestra gran masa de hermanos latinoamericanos hoy.

Por otro lado, dado el enfoque cristológico de esta presentación, es necesario aludir a los así denominados "cristólogos latinoamericanos", los cuales en su opción por el estudio, y algunos por el seguimiento del Jesús histórico, mencionan que en Jesucristo no sólo se nos ha revelado una verdad sobre Dios, sino además se nos ha revelado fundamentalmente una verdad sobre el hombre mismo, o mejor aún: el cómo del acceso del hombre a Dios es leído en clave antropológica, o dicho de otra manera, el encuentro con Jesucristo es el camino que necesariamente debemos recorrer los cristianos, para lograr nuestro destino escatológico, donde todas las cosas serán reconciliadas y recapituladas en él (Col 1:19; Ef 1:10).

En otros términos, Dios ha asumido en Jesús de Nazaret las características propias de la naturaleza humana, incluida la ineludible pertenencia del hombre a un pueblo concreto y a una tierra determinada. El «Hic de Virgine Maria Iesus Christus natus est» ${ }^{1}$, es una expresión colocada en Belén, precisamente en el lugar en que, según la tradición, nació Jesús; la misma, adquiere una peculiar

1 Por tanto, el misterio de la Encarnación transforma la experiencia universal del «espacio sagrado», por un lado restringiéndola y, por otro, resaltando su importancia con nuevos términos. En efecto, la referencia al espacio está implicada en el mismo «hacerse carne» del Verbo (cf. Jn 1:14). Dios ha asumido en Jesús de Nazaret las características propias de la naturaleza humana, incluida la ineludible pertenencia del hombre a un pueblo concreto y a una tierra determinada. 
resonancia desde Latinoamérica: aquí, la concreción física de la tierra y de su emplazamiento geográfico está unida a la verdad de la carne humana, asumida por el Verbo desde una historia de sufrimiento y dolor, de padecimiento y olvido, pero a la vez de gozo y esperanza en un porvenir mejor para nuestras naciones latinoamericanas.

Como se decía, en este recorrido cristológico, a lo largo y ancho de nuestra geografía latinoamericana, es imposible dejar de mencionar a nuestros teólogos y cristólogos. Nos encontramos en primer lugar con el teólogo Gustavo Gutiérrez, ahora fraile dominico, quien en su visión cristológica, expuesta en sus obras En busca de los pobres de Jesucristo, el pensamiento de Bartolomé de Las Casas (1992) y El Dios de la Vida (1989), dice que el principal fundamento bíblico en pro de esta praxis se encuentra en la encarnación de Jesús, el Cristo. La encarnación kenótica del Hijo de Dios es el ejemplo del ministerio de la Iglesia. En primera instancia, según este célebre teólogo peruano, el ministerio de Cristo entre los refutados y desechados de su tiempo, es un claro ejemplo para la Iglesia contemporánea. En un segundo momento, Gutiérrez realza el lugar que tiene la encarnación como "acto de amor": Cristo se hace hombre, muere y resucita para liberarnos y hacer que gocemos de libertad (Gal. 5,1). El Morir y el resucitar con Cristo es vencer a la muerte y entrar en una vida nueva.

La cruz y la resurrección sellan nuestra libertad, según Gutiérrez, como Jesús de Nazaret tomó en serio la realidad de los pobres de su tiempo, anunciándoles en primer lugar el mensaje del Reino. Hoy la realidad del mundo de los pobres y excluidos en Latinoamérica, debe ser tomada en serio, en caso contrario, la teología será acusada de complicidad y conveniencia con las injusticias presentes en nuestro mundo. Esto la obliga a pensar en el desafío de la práctica, buscando construir una sociedad que pueda anticipar las marcas del Reino en medio de la historia. La misma libertad de Cristo es vista por el teólogo peruano, como la dadora de libertad espiritual y económica.

Esta conclusión procede en buena medida de la concepción presente del reino de Dios, y de la irrupción de la escatología en la historia: la historia humana, vista desde Jesús, es una aventura al futuro, ella aparece como una tarea, como un quehacer socio-cultural, por medio de la cual el ser humano se orienta y se abre al don de la vida que da sentido a la historia misma: el encuentro definitivo y pleno con Jesús y con los demás seres humanos. De esta manera, la construcción de una historia, y consecuentemente de un presente más justo para todos los hombres, los orienta hacia el reino de Dios. Para Gutiérrez, la fe en Jesús, debe 
demostrarse con un compromiso auténtico con la situación de los seres humanos, especialmente los que sufren.

Por otro lado, encontramos la visión del teólogo brasileño Leonardo Boff, la cual ha procurado mostrar en Jesús una plenitud de humanidad tal, que precisamente ese hecho es por sí mismo el indicador de que únicamente es posible tal logro desde Dios mismo.

En efecto nos dice Boff: Humano como fue Jesús de Nazareth, en la vida, en la muerte y en la resurrección, sólo podía ser Dios mismo (Boff, 1977). Este teólogo brasileño, se propone pues, expresar las características propias de una cristología elaborada en América Latina, y así mismo buscar en Cristo respuesta a nuestras preocupaciones que son sólo nuestras, es decir, de los hombres que viven, trabajan y luchan en América Latina. Esta declaración de principio va seguida de una especificación muy precisa, tanto de las «características» como de las preocupaciones». ¿Qué es lo que caracteriza la cristología latinoamericana y la distingue de todas las otras? Boff responde, que la cristología elaborada «bajo nuestro cielo» presenta cinco notas configurantes y distintivas, a saber:

1. primacía del elemento antropológico sobre el eclesiológico

2. de lo utópico sobre lo factual

3. de lo crítico sobre lo dogmático

4. de lo social sobre lo personal

5. de la ortopraxis sobre la ortodoxia

Pero, ¿es verdad que la cristología que se escribe hoy presenta esas características sólo en América Latina? ¿Qué decir de los teólogos que suponen que hacen cristología crítica, practicando un método que asume las características o cualidades especificadas por Boff? Y ¿cuáles son las preocupaciones, las angustiosas preguntas para las cuales el hombre latinoamericano busca respuesta en la cristología?

Boff, en su última obra cristológica del 2009, titulada El Evangelio del Cristo cósmico, ha rescatado una antigua tradición: justamente la del Cristo cósmico. Textos que se remontan a los comienzos del cristianismo, especialmente a las reflexiones de san Pablo, en las que presentan a Cristo como cabeza del cosmos, pues se afirma que todo fue hecho por él, en él y para él. El teólogo brasileño, dice que Jesucristo no se encuentra sólo en las Escrituras, en la Iglesia o en el pan y el vino consagrados, su lugar natural es el cosmos. Y como el cosmos es el resultado de un inmenso proceso evolutivo, Cristo también es parte y fruto de ese proceso. Debe haber señales de él impresas en las circunvoluciones de este ya largo caminar de nuestro universo. 
Igualmente, es importante recordar que en el plano latinoamericano, es imposible dejar de mencionar otra gran obra de Boff, se trata de Ecología: grito de la tierra, grito de los pobres, en ella dice el pensador brasileño: "optar por el planeta Tierra como un todo orgánico, agredido y herido (geocidio), para que pueda continuar existiendo con el valor autónomo y relacional de todos los seres existentes en él" (Boff, 1977)..

Así mismo en su obra Ecología, Política, Teología y Mística, Boff, parte de la tesis básica de una visión ecológica que integra al ser humano con toda la naturaleza:

Todo se relaciona con todo y en todos los puntos. La babosa del camino tiene que ver con la galaxia más distante, la flor con la gran explosión ocurrida hace billones de años; la descarga de dióxido de carbono de un antiguo colectivo con nuestra Vía Láctea; mi conciencia con las partículas elementales subatómicas (Boff, 1977).

Lo original en Boff, es la forma como liga la reflexión cristológica con la ecológica, desde una concepción holística del universo ${ }^{2}$ : desde las partículas elementales hasta las galaxias, todas las cosas se encuentran interconectadas a una gran red de energía, tal como lo enunciara el mismo Marcus Chow, célebre autor del Universo Vecino y defensor de la Teoría de los superfilamentos3:

Los físicos están aceptando cada vez más la idea de que existen infinitas realidades amontonadas como las páginas de un libro sin fin. Por consiguiente existe un número infinito de versiones de nosotros mismos, que viven en un número infinito de vidas distintas en un número infinito de realidades paralelas. En alguna de estas realidades nunca abrimos este libro ni nunca empezamos a leer estas palabras (Chown, 2005: 42).

2 Holismo, del griego holos, que significa totalidad, término divulgado por el filósofo sudafricano Jan Smutts a partir de 1926, representa el esfuerzo de sorprender el todo en las partes y las partes en el todo. De esta forma se hace una síntesis que ordena, organiza, regula y finaliza las partes en un todo y cada todo con otro todo aún mayor.

3 Esta teoría defendida por Brian Greene, de la Universidad Cornell, y Marcus Chow, fundamentalmente indica que el cosmos entero está formado por una red intrincada y sutil de filamentos extremadamente delgados, en constante movimiento de vibración (como las cuerdas de una guitarra), que conducen una energía universal que se arremolina en forma de nodos o vórtices en los puntos donde se intersectan, y que estos filamentos son la tela de la que están formadas todas las cosas que existen, no solamente en la tercera dimensión, sino también en todas las otras dimensiones, es un concepto revolucionario que gana terreno a enormes pasos, y se anuncia como la nueva Revolución Cosmogónica de la época contemporánea.), hasta ahora irreconciliablemente separados por una brecha de para 
La obra de Teilhard de Chardin ${ }^{4}$ quiso recoger esos indicios y articularlos sistemáticamente en su propia época, con enormes resultados para nuevas lecturas de la figura de Jesucristo, que ha iluminado muchas vertientes teológicas y cristológicas a lo largo de varias décadas, entre las cuales se encuentra la teología sistemática de los siglos XIX y XX. Estudia teólogos como Usteri, Rothe, Dorner y Auberlen, que sientan los fundamentos bíblicos para introducir la idea de cosmología cósmica en la teología sistemática de autores como Martensen, Allan Galloway o Albert Frank-Duquesne.

En la segunda mitad del siglo XX destaca a Barth, Mascall, Dilchneider y Köberle. Resalta el valor de la ponencia de Joseph Sittler en Nueva Delhi, 1961, o también la perspectiva influyente de la teología dogmática clásica de Schmaus. Con más profundidad estudia, por último, a los teólogos Jürgen Moltmann ${ }^{5}$,

4 Para Teilhard, la evolución va desde la cosmogénesis a la biogénesis y desde ésta a la antropogénesis, que desemboca finalmente en la noosfera, trazándose así el arco que va desde el alfa al omega. Este Punto Omega, inmanente y trascendente, es identificado, como sabemos, con Cristo en la teología de Teilhard. Cristo es así el sentido profundo de la evolución del cosmos. Papanicolau hace también referencia a Karl Rahner que, bajo la influencia del pensamiento teilhardiano, trató de conciliar los principios de la filosofía-teología transcendental con la imagen de un cosmos evolutivo. Moltmann asume también la idea de evolución en la teología, pero con ciertos matices críticos dirigidos a Teilhard, Rahner y al New Age. La evolución ha producido el mal, hay víctimas del proceso, y como tal la evolución misma no es por sí salvadora, necesita una redención que irrumpe en la historia por el Jesús de Nazareth histórico. No hay, pues, una especie de gnosis cósmica que pueda identificar a Cristo con una armonía universal de un cosmos "feliz" que no existe. Esto introduce la temática de la cruz y el sufrimiento cósmico de Cristo. En primer lugar estudia la idea de la creación cruciforme de Holmes Rolston: la naturaleza evolutiva es cruciforme porque lleva el sufrimiento en cada proceso de avance. Pero la providencia ha asumido, y conduce a la salvación a este cosmos cruciforme, como nos muestra la imagen de Cristo que asume y salva el sufrimiento, no sólo personal sino cósmico también.

Según Teilhard el sufrimiento es también resultado inevitable del proceso de la misma evolución, aceptada como tal en el plan de Dios. De igual forma, autores como Barbour y Peacocke, asumen que el sufrimiento es consecuencia de la evolución creada por Dios y salvada por la obra redentora de Cristo. La obra teológica del dominico J.M. Maldamé, ofrece de nuevo una teología fundada en la evolución, donde la resurrección de Cristo se ve como el hecho final que permite dar sentido a la evolución cósmica.

5 Moltmann insiste en esta misma línea pero advierte que, para el cristianismo, la salvación y reconstitución final del cosmos no es una simple consecuencia de la evolución universal, ni algo exigido por una armonía universal, al estilo del New Age, sino una obra de Cristo que rompe con el mundo y establece una nueva creación. Sólo Cristo es capaz de reconocer el sufrimiento de un mundo no-armónico, repararlo y darle una nueva forma salvadora. 
en nuestro contexto, a Leonardo Boff ${ }^{6}$. Es así que la cristología cósmica ${ }^{7}$ recobra importancia en América Latina y en el mundo, puesto que busca no sólo entender las dimensiones de la realidad humana desde Jesucristo llegando a una reflexión sobre el universo sino, sobre todo, responder también a una búsqueda siempre presente en el espíritu humano: ¿cuál es el factor, la energía, el vínculo que hace que el ser humano se ligue al universo desde la idea de un cosmos y no un caos?

Se trata entonces, no sólo de un interés historiográfico sino también primordialmente existencial: ¿cómo concebir la unidad del todo?, ¿por cuáles caminos se revela?, ¿cómo elabora el cristianismo su respuesta? La pretensión final de Boff, es reforzar una lectura holística e integradora de la realidad, y animar una mística cósmica que abrace a las ciencias, las religiones, las tradiciones espirituales y la sensibilidad ecológica contemporánea. Desde luego, la figura de Jesucristo, emerge en su obra con un matiz nuevo y refrescante, pues leerlo desde nuestra realidad implica releer el evangelio, en clave de la "nueva creación", que significa una gigantesca reconciliación, que abarca todo.

No solamente se trata de revisar la relación del hombre con Dios, con las personas y con la sociedad, sino a toda la creación y sus relaciones con el Creador (Génesis 6:12), en este caso, Jesucristo significa la reconciliación del universo con Dios. Desde la cristología cósmica, la reconciliación con Dios significa desde luego, y especialmente también, la reconciliación entre los humanos, somos uno en Cristo, y ello significa el final de la discriminación por origen nacional, social o de género (Gálatas 2:28), la paz en la sociedad y entre los pueblos. La nueva creación significa el "hombre nuevo", la "mujer nueva", y la "vida nueva" ${ }^{8}$, la misma que tiene resultados palpables de reconciliación entre las personas y repercute en toda nuestra vida personal y social (Efesios 4:17-24).

6 Boff inserta el tema de la cristología cósmica en su conocida teología de la liberación. El hilo conductor, es para Boff, la teología de la resurrección por la que entendemos cómo Cristo, al resucitar, lleva consigo no sólo a la humanidad, sino a toda la creación. El Cristo que consuma una nueva creación por la resurrección lleva a cabo la liberación final del cosmos para que acoja a la humanidad.

7 A este diálogo sobre la ecología, han contribuido autores como Sittler, Fox, Moltmann y Boff. Tiene especial importancia la obra de Denis Edwards, Jesus the Wisdom of God: An Ecological Theology. Relaciona el tema bíblico de la sabiduría con Cristo como sabiduría de Dios, que consumará finalmente al universo por la transformación continua de cuanto existe.

8 La obra de Cristo es para la teología cristiana, además, la consumación cósmica final de la creación redimida. La resurrección de Cristo es el hecho que la realiza y anuncia. En cuanto la resurrección de Cristo abre paso a la resurrección personal de los hombres, y éstos son la síntesis más perfecta del contenido del cosmos. El mundo nuevo atisbado es también una nueva creación, en que el cosmos queda por Cristo consumado finalmente en Dios. 
Esta reflexión sobre el tema de la Cristología en América Latina, quedaría corta sin la referencia de otro gran teólogo, probablemente el principal cristólogo latinoamericano, se trata de Jon Sobrino. Su cristología se ha desarrollado a lo largo de, aproximadamente, veinticinco años de publicaciones. Es posible recoger sus consideraciones fundamentalmente en dos obras mayores: Jesucristo Liberador (Trotta: 1991) y Fe en Jesucristo. Ensayo desde las víctimas (Trotta: 1999).

En la obra de este importante teólogo vasco, radicado en San Salvador, la cristología, para abordar a su objeto Jesucristo, debe tener en cuenta dos cosas esenciales: la primera, y más obvia, es lo que el pasado nos ha entregado acerca de Él, es decir, textos en los cuales ha quedado expresada la revelación; la segun$\mathrm{da}$, menos tenida en cuenta, es la realidad de Cristo en el presente, esto es, su presencia actual en la historia a la cual corresponde la fe real en Cristo. Según esto, el lugar ideal de la cristología será aquel donde mejor se puedan comprender las fuentes del pasado, y donde mejor se capte la presencia de Cristo y la realidad de la fe en Él (JL 41).

Según Sobrino, el mecanismo fundamental para posibilitar la escandalosa situación descrita, ha consistido, dicho en forma de tesis, en lo siguiente: olvidar y recortar a Jesús de Nazaret, tergiversar así a Cristo y convertirlo frecuentemente en su contrario. Dicho de forma gráfica: de tal manera se ha presentado a Cristo, que el creyente, para serlo, no tenía porqué parecerse a Jesús, ni porqué seguir y realizar la misión de Jesús a favor de los oprimidos. Lo que Dios había unido, Cristo, el portador de las esperanzas mesiánicas y liberación de los oprimidos, fue separado y aun contrapuesto a través de la imagen de un Cristo sin Jesús (JL 30).

Para este teólogo, radicado en El Salvador, no serán suficientes las afirmaciones sobre la humanidad de Jesucristo, mientras en la praxis eclesial se mantengan actitudes de inhumanidad y de desconocimiento, de que alrededor nuestro, sencillamente hay personas que se debaten sobre el problema fundamental del ser humano: sobrevivir en este mundo hostil y articulado precisamente en contra del Reino. Finalmente, en Sobrino, el desconocimiento de la realidad de esta América indo-afro-latina. Realidad no sólo socioeconómica y política, sino también cultural y religiosa, de un continente que incluye hoy, cerca de la mitad de los fieles de la Iglesia Católica, es fuente de tergiversación del verdadero Jesús de la historia.

Esta realidad, tan sufrida y todavía esperanzada, y más globalmente, la realidad de una civilización del capital que produce masivamente gravísimas carencias, deshumanización de las personas, destrucción de la familia humana y grave amenaza a la supervivencia del planeta, afectará al Dios de Jesucristo, lo 
que es relevante para la teología cristiana en nuestro continente. Lo que llama la atención es que, aun cuando el diagnóstico de Sobrino tiene la virtud de explicitar taras muy ciertas de la cristología popular, pareciera no hacer contacto con la verdad radical de la fe en Cristo del pueblo latinoamericano, como si de ella dijera una verdad, pero no en su totalidad ni tampoco la más profunda.

Otro importante teólogo brasileño, que ha reflexionado sobre temas cristológicos es José Comblin; en su última obra: El Camino: ensayo sobre el seguimiento de Jesús. Comblin habla de la indignación de Jesús que procede del amor al pueblo. La indignación se vuelve todavía mayor cuando es provocada por los jefes religiosos, que tenían como misión enseñar las verdades y practicar la misericordia. Menciona además, la indignación que en el $4^{\circ}$ domingo de Adviento de 1511, en nombre de toda la comunidad dominicana, el fraile dominicano Antonio Montesinos, pronunció el famoso sermón en el que denunciaba los crímenes cometidos por los conquistadores y dueños de esclavos españoles. Fue un sermón pronunciado en la presencia de las principales autoridades del país, y terminaba con una sentencia de excomunión contra todos los que no liberasen a sus esclavos. De esta manera, Comblin se pregunta: ¿cómo no evocar la memoria de Bartolomé de las Casas, convertido que se hizo dominico y misionero en el actual Sur de México y en la hoy llamada América Central?

De las Casas fue hecho obispo de Chiapas, condenó los crímenes cometidos por los conquistadores, proclamó la injusticia de la conquista y defendió la causa de los indígenas durante 50 años. Para Comblin, el Reino que proclamó Jesús es la llegada del amor de Dios. Sin embargo, muchos no se interesan por él, están distraídos, viven con el mínimo empleo de las fuerzas de que disponen, hacen solamente lo indispensable para sobrevivir. El amor que proclama Jesús, requiere el empleo de mucha energía.

Juan Carlos Scannone, otro teólogo, da unas pistas cristológicas en Evangelización, cultura y teología (1990), diagnosticando que la fe en Cristo, expresada en una síntesis vital de lo humano y lo divino de Cristo, no es alienante, es más bien la clave hermenéutica y la fuerza última del pueblo creyente latinoamericano, a partir de la cual viven unificadas, integradamente, las exigencias de esta vida y de la otra. Scannone no ignora las deformaciones de la religiosidad popular, pero en vez de desarrollar las sospechas ideológicas sobre las imágenes de Cristo del pueblo latinoamericano, señala la pista principal de una nueva evangelización de Cristo en el continente, la cual consiste en asumir la riqueza humana y cristiana de la sabiduría y de la religión popular. En continuidad con la fe popular, Scannone propone injertar el nuevo anuncio de Jesucristo liberador, en la fe tradicional, en el Cristo Salvador. Sobrino, en cambio, propugna una ruptura: el nuevo 
anuncio de Jesucristo liberador, el Jesús histórico de los Evangelios, que debiera desplazar las imágenes alienantes de Cristo en cuanto causas precisas de la injusta miseria del continente.

\section{Retos y desafíos desde Latinoamérica y el Caribe}

El desafío, a decir verdad, es precisamente una cristología releída desde y para toda América Latina y el Caribe, que reconozca las distintas formas de concebir la cultura y la vivencia del cristianismo, en lugar de lecturas cristológicas importadas, antiguas o modernas, que sancionan religiosamente la injusticia con una tergiversada interpretación de la figura de Jesucristo. A la par, es importante escuchar el Magisterio de la Iglesia y atender al desafío mayor de una conversión del corazón, que erradique el egoísmo, la injusticia y la miseria por la vía de un seguimiento integral de Cristo, desde los signos de los tiempos actuales.

Otro desafío es el que plantea el teólogo norteamericano Paul Knitter, se trata de una cristología pluralista liberadora, la cual está dispuesta no sólo a valorar positivamente a otras religiones, sino que también tiene los medios para retarlas, para adoptar una postura clara y firme hacia ellas, por lo tanto, para evitar los peligros del relativismo. Dicha propuesta, no solamente está dispuesta a valorar positivamente y a trabajar con otras religiones, que están buscando promover el bienestar de la humanidad y del planeta, puede además retarlas con lo que es singular o distintivo acerca de la experiencia y el mensaje de Jesús: que en nuestros esfuerzos por promover el bienestar de todos, en una sociedad conformada por la compasión y la justicia, son las víctimas y los marginados quienes mejor nos van a mostrar el camino a seguir. Nuestra tarea, no sólo por ellos sino con ellos, es que debemos estar todos dispuestos a escucharles, a seguirles y a trabajar con ellos. Mientras los cristianos tienen seguramente mucho que aprender de otras religiones, este es el claro mensaje que tienen que anunciar enseñar y vivir.

Por otro lado, está el reto de una cristología de la creación, de la cual proviene la obligación para toda la humanidad de inventar un mundo mejor, poniendo en común esfuerzos diversos de imaginación y solidaridad. A este nivel, la exigencia hermenéutica de vincular al Jesús de la historia con el Cristo de la fe, se verifica en la mediación de Cristo con la cultura humana, por el establecimiento de un diálogo entre fe y razón, entre fe y ciencias, y entre fe y justicia. De lo contrario, el seguimiento de Cristo se hace ineficaz, en buena medida por ininteligible o por fundamentalista, pero puede también hacerse ideológico y promotor de "guerras santas". 
Cualquiera sea el caso, el reconocimiento de la fe popular en Cristo debiera ser clave hermenéutica para una correcta interpretación de la Escritura en América Latina. En definitiva, el seguimiento de Cristo es una interpretación de Cristo, es decir una interpretación espiritual, creativa de Cristo, que sólo puede hacerla el oyente de la Palabra y en sus propias categorías. La cristología latinoamericana tiene necesidad de un diagnóstico, porque de él desencadena, se lo diga o no, el tipo de evangelización de Cristo que se intentará. De hecho, en América Latina el anuncio de Cristo ha pasado por diversas etapas, lo ha sido en Medellín (Colombia), en Puebla (México), en Santo Domingo (República Dominicana) y Aparecida (Brasil). Ante esto, considero en suma, que la cristología en América Latina no sólo debiera conocer a fondo la fe popular en Cristo, además de las nuevas formas de experiencia religiosa o de increencia ofrecidas por doquier en un mundo cada vez más compartido, sino también diseñar un nuevo anuncio de Jesucristo, una nueva pastoral que dé legítima cabida a la fe efectiva en Jesucristo, porque es la única manera de valorar a los pobres, y a cualquier latinoamericano, como sujeto oyente e intérprete de la Palabra, y agentes de su propia historia.

Por último, la investigación histórico-crítica a nivel cristológico, siendo legítima y necesaria pero insuficiente, hace falta seguir profundizando en el tema del seguimiento y del compromiso cristiano, en el amplio panorama latinoamericano y caribeño: a Jesús sólo se le conoce de verdad cuando se le sigue. Esta afinidad y connaturalidad, es la que proporciona el seguimiento, la que permite hacer del discípulo seguidor; la práctica con espíritu de Jesús, que es lo más real, lo más histórico de Jesucristo en la misma historia.

\section{Referencias}

Blank, J. (1973). Jesús de Nazaret, historia y mensaje. Madrid : Cristiandad .

Boff, L. (1977). Jesucristo el Liberador: ensayo de cristología crítica para nuestro tiempo. Bogotá: Sal terrae.

Bornkamm, G. (1975). Jesús de Nazaret. Salamanca: Sígueme .

Chown, M. (2005). El universo vecino. Barcelona: La Liebre de Marzo.

Crossan, J., \& Reed, J. (2003). Jesús desenterrado. Barcelona: Crítica .

Dodd, C. H. ( 1984). El fundador del cristianismo. Barcelona: Herder.

Duquoc, C. (1972). Cristología. Ensayo dogmático sobre Jesús de Nazaret el Mesías. Salamanca : Sígueme .

Ehrman, B. (2001). Jesús, el profeta judío apocalíptico. Barcelona: Paidós. 
Fabris, R. (1998). Jesús de Nazaret, historia e interpretación. Salamanca : Sígueme.

Fiorenza, S. (2000). Cristología feminista crítica,. Madrid : Trotta.

Fuller, R. H. (1979). Fundamentos de cristología neotestamentaria. Madrid : Cristiandad .

Gnilka, J. (1995). Jesús de Nazaret, mensaje e historia. Barcelona : Herder.

Jeremias, J. (1993). Teología del Nuevo Testamento. Salamanca : Sígueme.

Kasper, W. (1989). Jesús, el Cristo. Salamanca : Sígueme.

Klausner, J. (1907). Jesús de Nazaret, su vida, su época, sus enseñanza (Primera ed.). Barcelona: Paidós.

León, D. (1966). Los evangelios y la historia de Jesús. Barcelona : Estela.

Meier, J. (1998-2003). Compañeros y competidores. Bogotá: Verbo Divino.

Meier, J. (1998-2003). Juan y Jesús. El reino de Dios. Bogotá: Verbo Divino.

Meier, J. (1998-2003). Los milagros. Estella: Verbo Divino.

Meier, J. (1998-2003). Un Judío Marginal. Las raíces del problema y de la persona. Bogotá: Verbo Divino.

Nisin, A. (1966). Historia de Jesús. Barcelona : Península .

Pannenberg, W. (1974). Fundamentos de cristología. Salamanca : Sígueme .

Sanders, E. P. (2001). La figura histórica de Jesús. Estella : Verbo Divino.

Schillebeeckx, E. (1983). Jesús la historia de un Viviente. Madrid: Cristiandad.

Schnackenburg, R. (1998). La persona de Jesucristo reflejada en los cuatro Evangelios. Barcelona : Herder.

Sobrino, J. (2010). Jesucristo Liberador. Madrid: Trotta

Theissen, G. (2002). La sombra del Galileo. Salamanca : Sígueme .

Theissen, G., \& Merz, A. (2000). El Jesús Histórico. Salamanca : Sígueme.

Trocmé, E. ,. (1974). Jesús de Nazaret, visto por los testigos de su vida. Barcelona : Herder. 